\title{
REVISITANDO O INÍCIO DA RACIONALIDADE FILOSÓFICO-CIENTÍFICA
}

\author{
Giorgio Borghi ${ }^{1}$ \\ Universidade Católica do Salvador (UCSal)
}

\begin{abstract}
RESUMO:
O presente artigo analisa a física pré-socrática como origem comum de filosofia e ciência, destacando que o esquecimento desta origem comum pode prejudicar tanto a filosofia como a ciência. A física pré-socrática envolve, em uma única busca, o que nos acostumamos a considerar como próprio da reflexão filosófica, e que tem uma dimensão essencialmente metafísica, e aquela investigação empírica que caracteriza o conhecimento científico. Mas a peculiaridade da física originária consiste na junção inextricável destas duas dimensões: antes da reflexão filosófica ser filosofia e da investigação empírica ser ciência, as duas foram, de forma nascente, "investigação sobre a physis". O aparecimento da racionalidade filosóficocientífica na Grécia antiga é normalmente considerado como uma passagem (a) do mythos ao logos, (b) de elaborações mais ou menos fantasiosas à observação da realidade e (c) de uma visão religiosa à uma visão profana e laica do mundo e da vida. $\mathrm{O}$ artigo analisa criticamente estas três questões para poder detectar traços constitutivos do código genético comum à filosofia e ciência.
\end{abstract}

PALAVRAS CHAVES: Física pré-socrática; Filosofia; Ciência.

\section{REVISITING THE BEGINNING OF PHILOSOPHICAL-SCIENTIFIC RATIONALITY}

\begin{abstract}
:
This article analyses pre-socratic physics as a common origin for science and philosophy, highlighting that overlooking this common origin may impair both philosophy and science. Pre-socratic physics involves, in one single pursuit, what we have accustomed ourselves to consider as inherent to philosophical thinking, which has an essentially metaphysical dimension, and the empirical investigation which characterizes scientific knowledge. But the singularity of original physics consists in the inseparable bonding of these two dimensions: before philosophical thinking became philosophy and
\end{abstract}

\footnotetext{
${ }^{1}$ Doutor em filosofia e professor da Universidade Católica do Salvador ( UCSal), Bahia Brasil. E-mail: giorgio.borghi@ucsal.br
} 
empirical investigation became science, both were, at their moment of birth, an "investigation about physis". The emergence of philosophical-scientific rationality in ancient Greece is usually considered as a passage (a) from mythos to $\operatorname{logos}$, (b) from somewhat fanciful conjecture to observation of reality and (c) from a religious view to a profane and secular view of world and life. The article critically analyzes these three questions in order to detect constitutive traces of the genetic code which is common to philosophy and science.

KEY WORDS: Pre-socratic physics; Philosophy; Science.

Tanto a história da filosofia como a história da ciência reconhece como berço comum de ambas a Grécia do VI século a. C. No caso da filosofia trata-se de algo óbvio, mas também no caso da ciência a convergência é unânime entre cientistas e filósofos.

\begin{abstract}
Na História da Ciência, um dos Períodos mais importantes e mais complexos foi o da Grécia Antiga, principalmente a partir do século VI antes da Era Cristã, pois foi quando se iniciou e se desenvolveu, pela primeira vez, o espírito científico, marco fundamental na evolução do pensamento humano, e quando ocorreria, em consequência, o advento da Ciência abstrata. (ROSA, 2012, p.99) (grifos nossos)

Os diferentes povos da Antiguidade - assírios e babilônios, chineses e indianos, egípcios, persas e hebreus -, todos tiveram visões próprias da natureza e maneiras diversas de explicar os fenômenos e processos naturais. Só os gregos, entretanto, fizeram ciência, e é na cultura grega que podemos identificar o princípio deste tipo de pensamento que podemos denominar, nesta sua fase inicial, de filosófico-científico. (MARCONDES, 2002, p.19) (grifos do autor)
\end{abstract}

Se considerarmos filosofia e ciência em sentido amplo, podemos dizer que sempre houve filosofia e ciência, desde o aparecimento do homo sapiens na face da terra, e da sua busca por sobrevivência e melhores condições de vida. Além disso, o desejo e a necessidade de procurar uma razão de ser do mistério do real, no qual estamos mergulhados, pertence à natureza humana e a qualifica como tal. Mas, em sentido estrito, é somente no mundo grego do VI sec. a.C. que filosofia e ciência aparecem. E, ainda assim, as palavras filosofia e ciência só assumem um significado parecido ao que usamos hoje somente no final do século $\mathrm{V}$ a.C. e, de forma mais sistemática, nos escritos de Platão.

A introdução do termo "filosofia" é atribuída a Pitágoras, quando teria explicado ao tirano Leon que, como nos jogos olímpicos se encontram os atletas que lutam pela glória, os mercadores atraídos pelo comércio e os espectadores que admiram as competições, assim na vida, além dos que estão interessados na glória ou nos negócios, existem pessoas que 
simplesmente se interessam pela contemplação da "natureza das coisas" e, por isso, se chamam de "filósofos". Esta tradição, que remete o aparecimento da palavra "filosofia" ao final do século VI, pode até ter um fundamento histórico, mas pode-se tratar também de uma projeção retrospectiva, proveniente do movimento pitagórico presente na Academia de Platão. Em todo caso, os primeiros empregos seguros da palavra "filosofia" aparecem por volta da metade do século V e podemos dizer que é definitivamente legitimada, como uma nova realidade cultural, somente por Platão, no século IV a.C.

Algo parecido acontece com a palavra ciência (episteme). A distinção entre verdadeiro conhecimento (episteme) e opinião (doxa) aparece pela primeira vez em Xenófanes (frg. 34), mas ainda sem a pretensão de indicar uma modalidade específica de conhecimento, que qualifique a episteme como disciplina distinta da filosofia. No próprio pensamento platônico, a palavra episteme aparece como o grau mais alto do conhecimento humano (veja alegoria da caverna). Assim, podemos concluir que, no período pré-socrático, é praticamente impossível demarcar uma distinção terminológica entre filosofia e ciência.

Com efeito, é vão querer atribuir a investigação sobre a natureza à ciência (certo tipo de ciência) ou à filosofia exclusivamente: sendo abundante o seu uso tanto em uma como em outra, ela não é nem uma nem outra, e pode se encaixar em uma ou em outra descrição, segundo o ângulo a partir do qual a consideramos. (LAKS, 2013, p.79-80)

Então podemos concluir que a filosofia e a ciência não nascem com as qualificações que estes nomes sugerem hoje, mas sim com o nome de "física", com toda a riqueza de significado que esta palavra carrega, e os responsáveis por este nascimento não são nem filósofos, nem cientistas, mas "pensadores originários", como os qualifica Heidegger. Podemos dizer, então, que o nascimento da filosofia e da ciência é determinado pelo desenvolvimento de um tipo de pensamento, que se caracteriza por uma forma específica de entender e explicar o universo. Filosofia e ciência nascem como física e a física pré-socrática se torna assim um elemento constitutivo do código genético tanto da filosofia como da ciência.

Aristóteles confirma esta convergência do nascimento contemporâneo de filosofia e ciência quando chama os mais antigos pensadores, de um lado, de "primeiros filósofos" e, do outro, de "físicos" (physikoi ou physiológoi). É comum encontrar nos escritos dos peripatéticos a atribuição do título "Perí physeos" às obras dos autores mais antigos, embora estes primeiros escritos provavelmente não tivessem nenhum título. Não é, portanto, correto dizer que "O desenvolvimento dos conhecimentos científicos se deveu a filósofos e físicos, porquanto ambos se propunham a uma explicação abrangente do Universo" (ROSA, 2012, p.107), porque não 
se trata de pessoas diferentes: os filósofos eram físicos e os físicos, filósofos.

Finalidade desta reflexão é tentar entender o sentido da física présocrática como origem comum de filosofia e ciência e destacar como o esquecimento desta origem comum pode prejudicar tanto a filosofia como a ciência.

\title{
A origem
}

Logo de início é importante esclarecer que não podemos considerar a "física" pré-socrática segundo a acepção moderna da palavra, assim como a palavra grega physis não revela toda sua riqueza de significado se equiparada à palavra "natureza", herdada da tradução latina natura' . Etimologicamente, a palavra physis tem relação com o que é originário e persistente e com o desabrochar que surge e se manifesta, e a "física" dos pensadores originários aparece como uma atitude de espírito que qualifica a nova forma de conhecimento como filosófico-científica.

Isso aparece claramente em Heráclito, que, no início da sua obra, apresenta a importância de compreender o Logos, conforme o qual tudo acontece, "distinguindo e explicando a natureza (physis) de cada coisa" (Frg.1, apud BORNHEIM, 2011, p.36). Distinguir e explicar a natureza de cada coisa é aquilo que pode nos permitir sintonizar com o Logos do universo e "homologein, falar assim como o Logos fala, quer dizer, corresponder ao Logos". (HEIDEGGER, 1996, p.32) É um pouco o significado da expressão 'peguei o sentido da coisa', isto é, fui envolvido pela força que faz com que a coisa seja e apareça como tal. Este conhecimento da physis é fundamental para Heráclito, embora seja um desafio constante, porque "a natureza (physis) ama esconder-se" (Frg.123, apud BORNHEIM, 2011, p.43). Este manifestar-se e retrair-se da physis é o que torna o processo do conhecimento humano um fenômeno essencialmente hermenêutico e o movimento de desocultamento da physis é o que os gregos chamam de alétheia.

\begin{abstract}
Neste sentido, não se pode dizer que os pensadores originários tematizaram o ser nos fragmentos que chegaram até nós. Mais que isso: em tudo que disseram deixaram o ser falar. É neste sentido que Heidegger entende que esses pensadores deixaram o ser falar em suas palavras fundamentais, quais sejam, phýsis, logos e alétheia. (CABRAL, 2009, p.112)
\end{abstract}

Physis indica um movimento de aparição, um eclodir do real que, no momento em que se desencobre, se manifesta como algo indisponível à nossa pretensão de posse. "Descemos e não descemos nos mesmos rios;

\footnotetext{
${ }^{2}$ Para uma analise mais detalhada da physis grega, confira KOIKE, 1999.
} 
somos e não somos" (Frg. 49a, apud BORNHEIM, 2011, p.39). No ato de aparecer, o rio e nós, "por natureza", somos e não somos. Para os pensadores originários não é possível reduzir a força que faz aparecer (a physis) ao que aparece (o real). Para eles, este nosso mundo "sempre foi, é e será um fogo eternamente vivo, acendendo-se e apagando-se conforme a medida" (Frg. 30, apud Idem, p.38).

Como não lembrar a sarça ardente de Moisés? "Moisés olhou, e eis que a sarça ardia no fogo, e a sarça não se consumia. Então disse Moisés: 'Darei uma volta e verei este fenômeno estranho; verei por que a sarça não se consome"." (Ex. 3,1-3) A physis se manifesta como algo que nos questiona, nos interpela, nos espanta como um fogo "eternamente vivo", que sempre arde e não consome. Fazer o que? O jeito é chegar mais perto e tentar entender. $\mathrm{O}$ conhecimento começa e continua com a capacidade de se deixar mover pelo "espanto" deste fogo que arde sem parar.

É por força de seu maravilhamento que os seres humanos começam agora a filosofar e, originalmente, começaram a filosofar; maravilhando-se primeiramente ante perplexidades óbvias e, em seguida, por um progresso gradual, levantando questões também acerca das grandes matérias, por exemplo, a respeito das mutações da lua e do sol, a respeito dos astros e a respeito da origem do universo" (Arist,, Metaph., 982b 12-17).

Pertence ao código genético de qualquer tipo de busca de conhecimento este espanto que desencadeia o pensar como abertura ao mistério da realidade que irrompe nas realizações do real. Trata-se de um pensar que Aristóteles chama de filosofar e que leva a se maravilhar não somente ante as grandes questões, como a origem do universo, mas também ante o que o senso comum considera como óbvio.

No conceito grego de physis, estavam, indivisas, as duas coisas: o problema da origem - que obriga o pensamento a ultrapassar os limites do que é dado na experiência sensorial e a compreensão, por meio da investigação empírica, do que deriva daquela origem e existe actualmente. (JAEGER, 1979, p.182)

Assim, a física pré-socrática envolve, em uma única busca, o que nos acostumamos a considerar como próprio da reflexão filosófica, e que tem uma dimensão essencialmente metafísica, e aquela investigação empírica que caracteriza o conhecimento científico. Mas a peculiaridade da física originária consiste na junção inextricável destas duas dimensões: antes da reflexão filosófica ser filosofia e da investigação empírica ser ciência, as duas foram, de forma nascente, "física", "investigação sobre a physis" (perí physeos historia). 


\begin{abstract}
Pensando a physis, o filósofo pré-socrático pensa o ser, e a partir da physis pode então aceder a uma compreensão da totalidade do real: do cosmos, dos deuses e das coisas particulares, do homem e da verdade, do movimento e da mudança, do animado e do inanimado, do comportamento humano e da sabedoria, da política e da justiça. (BORNHEIM, 2011, p.14)
\end{abstract}

Por isso, qualificar o período pré-socrático como cosmológico, contraposto a um período antropológico que iniciaria somente com Sócrates e os Sofistas, significa assumir a noção de physis originária de forma redutiva. Para os pensadores originários pensar a physis significava procurar entender de forma nova o mundo em que viviam e, consequentemente, repensar a si próprios e suas relações com o divino e com os outros seres animados e inanimados. A busca para uma nova compreensão do universo físico não caminha separada da busca pela compreensão do ser humano neste universo. "Eu me procurei a mim próprio", diz o fragmento 101 de Heráclito, e talvez tenha sido justamente esta reflexão sobre a "natureza" humana a inspirar a ideia do devir como critério interpretativo da "natureza" de todo o universo.

Para melhor entender a novidade e a peculiaridade da física présocrática, vamos revisitar três questões relacionadas com o início da racionalidade filosófico-científica na Grécia antiga. Quando se fala deste início, se apresenta este nascimento como uma passagem (a) do mythos ao $\operatorname{logos}$, (b) de elaborações mais ou menos fantasiosas à observação da realidade e (c) de uma visão religiosa à uma visão profana e laica do mundo e da vida. Considero fundamental analisar criticamente estas três questões para poder detectar traços constitutivos do código genético comum à filosofia e ciência.

\title{
Do mito à razão?
}

Ao falar da origem grega da filosofia e da ciência, é comum escutar um tipo de linguagem que poderia levar a pensar que somente na Grécia do VI século a.C. aparece a racionalidade. Fala-se do nascimento da filosofia como da passagem do mito à razão ou até de "invenção da razão", quando seria mais correto e menos suscetível de equívocos falar do desenvolvimento de uma nova forma de racionalidade. A racionalidade humana aparece bem antes do aparecimento da racionalidade filosóficocientífica, e todas as tentativas do ser humano de entender o mundo e si próprio no universo, sejam elas de tipo mágico, religioso, mítico, são manifestações, às vezes altamente desenvolvidas, de racionalidade. "Daí por que o pensamento racional, ninguém o 'inventou', e nenhum povo ou cultura (dadas as necessidades e os modos específicos de atendê-las) o 
absorveu por inteiro ou o recolheu com exclusividade". (SPINELLI, 2006, p. 45-46)

Considerando mais diretamente a questão do mito, não podemos esquecer que mythos, tanto como logos, quer dizer palavra. "No princípio era a Palavra...". Há sempre uma "palavra" no começo e esta palavra é essencial para que o mundo se torne mundo humano. No livro bíblico do Genesis, é a palavra divina que cria, mas é o homem que nomeia e significa o que Deus a ele conduz. O ser humano é "animal racional" enquanto "ser de linguagem", e a primeira forma de linguagem é sua própria existência, palavra mais vivida do que tematizada e que é de ordem mítica, englobando as várias dimensões da experiência integral do homem, inclusive a própria racionalidade. Trata-se aqui de uma experiência de conhecimento primeira, de uma "palavra" que pronuncia tacitamente o mundo e a vida. Esta primazia da palavra mítica nos convida a inverter a famosa máxima de Descartes de Cogito ergo sum em Sum ergo cogito.

Assim podemos dizer que o mito é um saber originário e fundante de uma "razão humana engajada" e que se traduz numa forma de vida.

O mito é a forma de vida que a ciência, embora almeje, jamais será. E se a ciência pretende transformar-se numa forma de vida, como pode bem nos parecer na civilização altamente tecnicista de hoje, só o será miticamente. A ciência só destrói um mito criando outro: o de si mesma. (MOURA apud MORAIS, 1988, p.50)

Afinal, a distinção entre mito e razão mais que uma distinção substancial é uma distinção funcional. Isso significa que o mito é uma manifestação de racionalidade e que a razão pode se manifestar em forma mítica.

Então, o que aconteceu na Grécia de VI século a. C. para poder dizer que nasce a filosofia e a ciência? Muito oportunamente, Bornheim (2011, p.9-10) observa que "O itinerário do pensamento pré-socrático não se desdobra do 'mito ao logos', mas de um logos mítico para a conquista de um logos mais acentuadamente noético". Mas o logos noético não pode perder o contato com o logos mítico, sob pena de prejudicar a possibilidade de acesso ao mistério da verdade, pronunciado originariamente pela "palavra" mítica.

O progresso do logos noético, emancipado do logos mítico, levou a uma espécie de estilhaçamento daquilo que o mito guardava em profunda unidade: arte, técnica, política, religião, enfim, todas as funções relacionadas ao universo humano. O logos dos pensadores originários mantinha clara a percepção de uma profunda unidade: "É sábio que os que ouviram, não a mim, mas as minhas palavras $(\log o s)$, reconheçam que todas as coisas são um" (Frg.50 apud BORNHEIM, 2011, p.39). Depois, sobretudo com o advento da modernidade, o desenvolvimento autónomo da 
razão lógico-matemática, provoca a emancipação de cada função especializada, cada uma tentando compor, por própria conta, a unidade perdida. Mas o ser humano não consegue viver estilhaçado em partes especializadas, e o anseio pela unidade, que se manifesta de várias formas, revela o homem como um ser irremediavelmente mítico, se considerarmos como próprio do mito a estrutura unitária do viver e da sua percepção.

O pensamento de Heidegger oferece uma contribuição ímpar para uma revisão do nosso modo de ver e viver a racionalidade. Trata-se, para ele, de recuperar a força do que foi pensado, no impensado, "do qual o que foi pensado recebe seu espaço essencial" (HEIDEGGER, 1996, p.188). Distanciando-se da posição do saber absoluto de Hegel, que "sobressume" toda a história do pensamento, identificando real e racional, Heidegger fala da necessidade de um "passo de volta". "O passo de volta aponta para o âmbito, até aqui saltado, a partir do qual a essência da verdade se torna, antes de tudo, digna de ser pensada" (Idem. p.189).

A emancipação total do logos em relação ao mito é um preconceito moderno que implica uma ilusória transparência total ou saber absoluto. Tanto no âmbito da filosofia, como naquele da ciência, uma sadia articulação entre mythos e logos permite que o mythos fecunde o logos, enquanto o logos procura desvendar as múltiplas variações do mito. "A razão impulsionada a articular sentido precisa refazer um caminho de volta para encontrar a origem do espanto gerador da interpelação e, aí, o logos projeta-se ao distante começo, só alcançado pelo mito". (ALMEIDA, 2002, p.224) Assim, o logos filosófico ou científico pode encontrar o caminho da própria realização na relação com o mito, na contínua tentativa de interpretar a misteriosa unidade do real, como aconteceu na física présocrática.

\title{
Observação ou teoria?
}

A segunda questão a ser analisada é aquela relativa ao aparecimento da racionalidade filosófico-científica como passagem a uma prática cognoscitiva mais observacional.

\begin{abstract}
A epistemologia empirista tradicional e a historiografia tradicional da Ciência estão profundamente influenciadas pelo mito baconiano de que toda a ciência começa pela observação e só depois avança, lenta e cuidadosamente, para as teorias. Que os factos são muito diferentes é o que podemos aprender com o estudo dos primeiros Pré-Socráticos. (POPPER, 2006, p.191)
\end{abstract}

A água de Tales é o primeiro e emblemático caso de elaboração de uma "teoria" que representa uma grande novidade no contexto cultural em que aparece e que coloca a questão do seu estatuto epistemológico. Quando Aristóteles fala de Tales, na Metafísica, elabora aquela que poderíamos 
considerar a primeira definição do método científico como aquilo que nos permite deduzir hipóteses e leis gerais a partir de observações e experimentos: "Tales, iniciador desse tipo de filosofia, diz que o princípio é a água [...], certamente tirando esta convicção da constatação de que..." (983b 19-22). Neste sentido, Tales seria o primeiro cientista, mas, significativamente, nesta mesma passagem, Aristóteles qualifica Tales como "iniciador desse tipo de filosofia".

Segundo a interpretação de Nietzsche, no seu escrito A filosofia na época trágica dos gregos, a hipótese da água, que precisamos levar a sério porque enuncia algo sobre a origem das coisas "sem imagem e fabulação", é algo que Tales não poderia ter deduzido das "parcas e desordenadas observações da natureza empírica". O que levou Tales àquela que Nietzsche chama de "monstruosa generalização"

foi um postulado metafísico, uma crença que tem sua origem em uma intuição mística e que encontramos em todos os filósofos, ao lado dos esforços sempre renovados para exprimila melhor - a proposição: 'Tudo é um'. (NIETZSCHE, s/d, p.16)

Nietzsche destaca, assim, os postulados metafísicos, as crenças baseadas em intuições, como algo que pertence ao código genético da filosofia e da ciência enquanto tal. E, no mesmo escrito sobre a filosofia grega, encontramos uma passagem em que ele contrapõe criticamente esta visão da física pré-socrática à visão da ciência imperante no positivismo do seu tempo.

Quando Tales diz: "Tudo é água", o homem estremece e se ergue do tatear e rastejar vermiformes das ciências isoladas, pressente a solução última das coisas e vence, com esse pressentimento, o acanhamento dos graus inferiores do conhecimento. $\mathrm{O}$ filósofo busca ressoar em si mesmo o clangor total do mundo e, de si mesmo, expô-lo em conceitos. (NIETZSCHE, s/d, p.18)

Nota-se novamente como não existe, neste texto, uma linha divisória definida entre ciência e filosofia. Nietzsche considera Tales como um cientista que supera o acanhamento dos graus inferiores do conhecimento das ciências positivas isoladas, que rastejam como vermes, mas reconhece que faz isso em quanto filósofo, que deixa ressoar em si a totalidade do universo.

Será bom recordar, de vez em quando, que a nossa ciência ocidental (e não parece haver nenhuma outra) não começou por nenhuma coleção de observações de laranjas, mas sim por audaciosas teorias acerca do mundo. (POPPER, 2006, p.191) 
Isso se aplica também às primeiras teorias acerca da forma e da posição da Terra. Sabemos que Tales considerava a Terra como um barco flutuando na água, mas Anaximandro, analisando criticamente esta hipótese, concluiu que a Terra não está apoiada em nada, mantendo-se imóvel por causa da sua equidistância em relação a tudo o resto. Segundo Popper, Anaximandro chega a esta conclusão, não pela observação, e sim pela crítica teórica à hipótese de Tales.

A hipótese de Tales é a típica teoria que desemboca numa regressão infinita: se a Terra se apoia na água, em que se apoia a água? Precisamos encontrar um suporte para o oceano e, a seguir, um suporte para este suporte, e assim ao infinito. O jeito é recorrer a "postulados" e "intuições" que possam nos ajudar na elaboração de outra hipótese explicativa. Anaximandro recorre à simetria estrutural do mundo, elaborando uma das ideias mais ousadas do pensamento humano, e antecipando, em certo sentido, a ideia newtoniana de forças gravitacionais imateriais.

De outro lado, Anaximandro teoriza que a Terra tem a forma de um tambor e que nós andamos numa das suas superfícies planas. Popper se pergunta o que foi que impediu a Anaximandro de deduzir da sua anterior teoria sobre a posição da Terra, a hipótese de que a Terra fosse um globo, e não um tambor. Sua resposta é a seguinte:

Não pode haver dúvidas: foi a experiência observacional que lhe ensinou que a superfície da Terra era, de uma maneira geral, plana. Terá sido, por conseguinte, um raciocínio especulativo e crítico, a discussão abstracta e crítica da teoria de Tales, o que quase o conduziu à teoria verdadeira acerca da forma da Terra. E foi a experiência observacional que o desencaminhou. (POPPER, 2006, p.193)

Também em relação ao princípio originário que Anaximandro estabelece no lugar da água de Tales, podemos constatar esta capacidade de ultrapassar as aparências sensíveis. O apeiron não é nenhum elemento determinado e, segundo o único fragmento de Anaximandro que conhecemos, a constituição de todos os elementos se dá justamente pela saída do apeiron. Uma saída que determina uma ruptura na unidade originária e que, portanto, será compensada com a reconstituição da unidade, pois as coisas "pagam umas às outras castigo e expiação pela injustiça, conforme a determinação do tempo" (ANAXIMANDRO apud BORNHEIM, 2011, p.25).

Com isso, Anaximandro elabora a ideia de uma legalidade universal da natureza, podendo ser considerado legitimamente o primeiro teórico do mundo como cosmos, como "harmonia invisível à visível superior" (Cfr. frg.54 de Heráclito), governada pela Dike eterna. "Essa descoberta não podia fazer-se noutro lado senão no fundo da alma humana. Nada se teria 
podido fazer com telescópios, observatórios ou qualquer outro gênero de investigação empírica". (JAEGER, 1979, p.187)

Podemos, então, concluir que na física dos pensadores originários encontramos também a superação da dicotomia entre método dedutivo e método indutivo. $\mathrm{Na}$ realidade, não existe nenhum processo de conhecimento científico que parta unicamente da experiência. A observação e a experiência entram no processo de conhecimento desempenhando apenas papel de argumentos críticos, juntos com outros argumentos de caráter não observacional.

\section{0 que filosofia e ciência fizeram de Deus?}

Uma terceira questão que merece a nossa atenção é a questão da relação de filosofia e ciência com a religião. Apresentando os inicios da racionalidade filosófico-científica grega como um fenômeno que se contrapõe à mitologia, que era a forma religiosa oficial do momento, se chega à conclusão de que a nova forma de racionalidade se contrapõe à religião em quanto tal e a qualquer tipo de compreensão do mundo e da vida que não seja estritamente racional. Ora a física pré-socrática mostra que não é bem assim e que, como no caso de mito e razão, aqui também se trata não da passagem da religião ao ateísmo, mas sim do nascimento de uma nova forma de relação com o "divino", bem mais refinada do que a anterior.

A filósofa espanhola Maria Zambrano (1995, p.25) abre o primeiro capítulo do seu livro $O$ homem e o divino com a seguinte afirmação: "Uma cultura depende da qualidade dos seus deuses". Neste sentido, podemos dizer que a passagem da mitologia à racionalidade filosófico-científica se apresenta como uma mudança cultural determinada pela diferença qualitativa da percepção do mistério inerente à realidade.

Pois a acção por excelência da filosofia foi a transformação do sagrado no divino, na pura unidade do divino. E para realizar esta acção impremeditada de transformar o sagrado no divino, o pensamento filosófico teve de ignorar os deuses, imagens. (ZAMBRANO, 1995, p.67-68).

O sagrado nasce da pretensão do saber humano de conhecer e controlar o mistério. Transformar o sagrado no divino significa aceitar de não poder abarcar totalmente a riqueza inesgotável do mistério da vida e do mundo e ter a coragem de mergulhar na escuridão de um não saber, onde formular novamente a pergunta mais simples e mais radical: "o que é isso?" Esta pergunta revela uma nova percepção da transcendência da verdade.

É este retrocesso ao divino que dá inicio ao pensamento filosóficocientífico. Um retrocesso que, descendo as camadas cada vez mais profundas da ignorância, nos leva no âmago das trevas originárias da realidade e do ser, onde as imagens sagradas da mitologia não satisfazem 
mais. Sim, porque os antigos mitos gregos não podem ser considerados simplesmente como curiosas histórias de seres fabulosos chamados deuses, mas como a tentativa de sondar e 'compreender' a profundidade oculta da realidade. Quando Tales elabora a sua hipótese da água como princípio de todas as coisas, está procurando uma nova forma de resposta às mesmas questões das quais se tinha originado o pensamento mitológico. Por isso, mais que uma hipótese científica, no sentido atual da palavra, está propondo uma nova atitude de conhecimento da realidade, que se fundamenta numa nova concepção do divino.

O próprio Aristóteles lembra que Tales teria apresentado uma segunda tese, aparentemente contraditória com aquela, mais conhecida, da água: "Tudo está cheio de deuses". Será que essas duas teses, a da água e a dos deuses, são afirmações conflitantes, ou será que elas indicam o caminho para a verdadeira compreensão do sentido que a teoria de Tales tinha, na época em que foi formulada? Como já vimos, Aristóteles fala de Tales, como do primeiro pensador a usar um método "científico": "Tales, iniciador desse tipo de filosofia, diz que o princípio é a água [...], certamente tirando esta convicção da constatação de que..." (983b 19-22); mas depois continua, dizendo:

Há também quem acredite que os mais antigos, que por primeiro discorreram sobre os deuses, muito antes da presente geração, também tiveram essa mesma concepção da realidade natural. De fato, afirmaram Oceano e Tétis como autores da geração das coisas, e disseram que aquilo sobre o quê juram os deuses é a água, chamada por eles Estige. (Arist., Metaph., 983b 28-33).

Esta evocação, feita por Aristóteles, do antiquíssimo saber mítico sobre o Oceano, Tétis e Estige, o lendário rio original, e a surpreendente menção aos "que por primeiro discorreram sobre os deuses", que coloca também Tales entre aqueles que especularam a respeito dos deuses, nos oferece uma preciosa sugestão interpretativa do pensamento dele, que supera o aparente conflito entre suas teses. Quando fala da água, Tales está tentando dizer algo sobre o mistério da origem, sem recorrer às imagens sagradas da mitologia.

Do mesmo modo que a água dá vida às coisas, assim também se passa com o fundamento divino originário: vivifica tudo o que penetra. Desse modo, a frase de Tales sobre a originariedade da água pretende afirmar o seguinte: em todo o real atua uma força divina, de poder criador, assim como o rio originário do mito, que tudo penetra como a mantenedora da vida, a água. (WEISCHEDEL, 2000, p.22-23).

Isso nos ajuda a entender a natureza originária da filosofia e da ciência, como aparece na física pré-socrática. Mais do que elaborações de 
uma ciência natural primitiva, as teorias dos pensadores originários representam a tentativa de responder de forma renovada às perguntas de sempre sobre a natureza oculta do universo. As respostas religioso-culturais da mitologia não satisfazem mais, mas as perguntas continuam em pé, nascendo da percepção e da convicção que o real não se identifica simplesmente com o que aparece, mas tem uma profundidade. Encontrar um novo caminho (método) para investigar essa profundidade é o que determina o aparecimento de um "tipo de filosofia" cujo iniciador seria Tales.

O discípulo de Tales, Anaximandro, continua e aprofunda este novo caminho, com a ideia genial do apeiron, que, pela própria formulação privativa, indica, ainda mais claramente, aquele retrocesso à ignorância de onde nasce a nova atitude filosófico-científica, na busca de um divino originário sem imagens, sem definição (indefinido), sem limite (ilimitado). Mas quem primeiro tematizou a transformação do sagrado no divino, operada pela racionalidade filosófico-científica, foi Xenófanes de Cólofon com sua crítica ao antropomorfismo da mitologia.

Tivessem os bois, os cavalos e os leões mãos, e pudessem, com elas, pintar e produzir obras como os homens, os cavalos pintariam figuras de deuses semelhantes a cavalos, e os bois semelhantes a bois, cada (espécie animal) reproduzindo a sua própria forma. (Frg.15 apud BORNHEIM, 2011, p.32)

A vontade de verdade, como diria Nietzsche, leva o ser humano a querer, de qualquer jeito, dispor dela, pintando-a a sua imagem e semelhança, criando simulacros que possam dar a ilusão de dispor dela quando e como deseja. Mas o filósofo descobre que a verdade, na sua profundidade originária, é divina e, como tal, é sempre mais: "Um único deus, o maior entre deuses e homens, nem na figura, nem no pensamento semelhante aos mortais" (Frg.23 apud Idem, p.33). Esta 'profissão de razão' monoteísta abre o caminho para a ideia do Ser de Parmênides, como tradução da dimensão profunda e misteriosa da realidade. Como observa Heidegger, "De há muito, o mistério nos foi proposto na palavra 'ser'. É por isso que o 'ser' é apenas uma palavra provisória, no sentido de palavra precursora". (HEIDEGGER, 2002, p.203) Considerar esta dimensão transcendente da verdade é o que permite o regresso do sagrado ao divino, com relativa renuncia a toda forma de dogmatismo antropomórfico, tanto na filosofia como na ciência.

Pois homem algum viu e não haverá quem possa ver a verdade acerca dos deuses e de todas as coisas das quais eu falo; pois mesmo se alguém conseguisse expressar-se com toda exatidão possível, ele próprio não se aperceberia disso. A opinião reina em tudo. (Frg.34 apud BORNHEIM, 2011, p.33) 
A verdade que a física dos pensadores originários está procurando é "a verdade acerca dos deuses e de todas as coisas". Uma verdade, portanto, que requer uma atitude de espírito (espiritualidade) que, não satisfeita com as formulações antropomórficas, nem com as elaborações antropocêntricas, sabe mergulhar na escuridão luminosa do mistério da vida, experimentando a cada dia a dor e a alegria do pensar. Esta nova atitude de espírito torna a vida digna de ser vivida, porque nos liberta tanto da arrogância do saber como da angústia da ignorância.

\section{Considerações finais}

Quando falamos em física pré-socrática, aceitamos a ideia de que a figura de Sócrates constitui uma linha divisória na história do pensamento ocidental. Já na antiguidade, encontramos pelo menos duas interpretações desta demarcação da filosofia socrática em relação ao pensamento anterior. A primeira, representada, sobretudo, pela perspectiva platônico-aristotélica, considera Sócrates como o responsável pela passagem de uma filosofia das coisas físicas a uma filosofia do conceito. A segunda, de origem mais ciceroniana, interpreta Sócrates como filósofo que abandona uma filosofia da natureza, para focalizar uma filosofia do homem.

A segunda interpretação revela uma compreensão redutiva da physis dos primeiros pensadores, por isso considero como mais relevante e decisiva para o futuro da filosofia e da ciência a interpretação platônico-aristotélica do sentido de "pré-socrático". De fato, com o Sócrates de Platão, "a harmonia é rompida, o ser passa a ser interpretado ou concebido fora do aparecer do ente, e a verdade deixa de se referir ao movimento de descobrimento da totalidade do real" (CABRAL, 2009, p.116).

Hoje estamos cada vez mais percebendo que esta separação acaba prejudicando tanto a ciência como a filosofia. Popper observa que o que interessa realmente é procurar entender o mundo em que vivemos e, consequentemente, nós próprios que vivemos neste mundo.

\footnotetext{
Para mim, tanto a Filosofia como a Ciência perdem todo o seu poder de atração quando renunciam a essa busca - quando se convertem em especializações e deixam de ver e de se intrigar com os enigmas do nosso mundo. A especialização pode ser uma grande tentação para o cientista. Para o filósofo, é o pecado mortal. (POPPER, 2006, p.189)
}

Recuperando uma terminologia heideggeriana, podemos dizer que toda forma de conhecimento que pretende dizer o ente em detrimento do ser, ou falar do ser como se fosse um ente, é um pensamento calculador e não originário. "O desafio que se instaura, hoje, ao Dasein é fazer a experiência do salto e ver o real desde sua dimensão genética, desde o vigor do ser". (CABRAL, 2009, p.131) Trata-se de uma nova forma de pensar e de dizer o 
ser, que pode inaugurar um novo caminho e um renovado encontro entre filosofia e ciência. Na perspectiva de Heidegger, o ser humano se compreende, quando compreende o ser e compreende o ser quando compreende a si próprio.

Quero finalizar estas reflexões com uma passagem da preleção de Heidegger sobre que é a metafísica, que apresenta sinteticamente o foco de toda a presente reflexão.

\begin{abstract}
A aparente sobriedade e superioridade da ciência se transforma em ridículo, se não leva a sério o nada. Somente porque o nada se revelou, pode a ciência transformar o próprio ente em objeto de pesquisa. Somente se a ciência existe graças à metafísica, é ela capaz de conquistar sempre novamente sua tarefa essencial que não consiste primeiramente em recolher e ordenar conhecimentos, mas na descoberta de todo o espaço da verdade da natureza e da história, cuja realização sempre se deve renovar. (HEIDEGGER, 1996, p. 62)
\end{abstract}

É necessário lembrar que o que Heidegger entende aqui por metafísica é a mesma coisa que Nietzsche entende quando considera a água de Tales "um postulado metafísico". Por isso, é aquilo que pode permitir à ciência "conquistar sempre novamente sua tarefa essencial". E as aquisições da ciência e da filosofia serão sempre provisórias, porque o objeto último delas é a physis, isto é, algo que continuamente brota e que só neste constante brotar revela e esconde sua verdade. Talvez a fecundidade da física pré-socrática esteja também no fato de ter chegado até nós não em forma de tratados, e sim sob forma de fragmentos.

Platão, na Carta VII, talvez decepcionado pelo fracasso na sua tentativa de instruir Dionísio de Siracusa, teoriza que quando alguém coloca por escrito alguma coisa significa "que isso não era para ele o mais sério, pois, se for sério, repousa em sua parte mais nobre". (Pl., Ep., 344c) E quem "tenha escrito algo sobre os primeiros e supremos elementos da natureza (peri physeos arkon kai próton), não ouviu nem aprendeu nada de são daquilo que escreveu. Pois, de modo semelhante a mim, ele teria respeitado essas coisas e não as teria ousado expor em desarmonia e inconveniência" (Idem, 344d).

O fragmento se situa entre o tratado sistemático e o silencio, respeita "os primeiros e supremos elementos da natureza" e, como o oráculo de Delfos, "nem diz nem oculta, mas dá sinais". (Cfr. frg. 93 de Heráclito) Por isso, deixa o ser ser; deixa que o mistério do real subsista como mistério, fecundando o nosso pensamento e permitindo assim a constante renovação das realizações do nosso conhecimento filosófico-científico. 


\section{Referências bibliográficas}

ALMEIDA, C. L. S. de. (2002). Hermenêutica e dialética: dos estudos platônicos ao encontro com Hegel. Porto Alegre: EDIPUCRS.

ARISTÓTELES. Metafísica Apud REALE, G. (2001). Ensaio introdutório, texto grego com tradução e comentário. Trad. M. Perine. São Paulo: Loyola.

BORNHEIM, G. A. (Org.). (2011). Os filósofos pré-socráticos. - 19ª ed. São Paulo: Cultrix.

CABRAL, A. M. (2009). Heidegger e a destruição da ética. Rio de Janeiro: Editora UFRJ; Mauad Editora.

HEIDEGGER, M. (1996). Conferências e escritos filosóficos. Trad. E. Stein. São Paulo: Nova Cultural.

. (2002). Ensaios e conferências. Trad. E. Carneiro Leão, G. Fogel, M. S. C. Schubach. - $2^{\mathrm{a}}$ ed. - Petrópolis: Vozes.

JAEGER, W. (1979). Paidéia: a formação do homem grego. Trad. A. M. Parreira. São Paulo: Martins Fontes.

KOIKE, K. (1999). Aspectos da physis grega. Revista Perspectiva Filosófica - Vol. VI - n ${ }^{\circ}$ 12, p. 165-178.

LAKS, A. (2013). Introdução à "filosofia pré-socrática". Trad. Miriam C.D. Peixoto. São Paulo: Paulus.

MARCONDES, D. (2002). Iniciação à história da filosofia. Dos présocráticos a Wittgenstein. - $7^{\mathrm{a}}$ ed. - Rio de Janeiro: Jorge Zahar.

MORAIS, Regis de (Org.). (1988). As razões do mito. Campinas, São Paulo: Papirus.

NIETZSCHE. F. (s/d). A filosofia na idade trágica dos Gregos. Trad. R.R.Torres Filho. Lisboa: Edições 70.

PLATÃO. (2008). Carta VII. Trad. J.T. Santos e J. Maia Jr. Rio de Janeiro: Ed. PUC; São Paulo: Loyola.

POPPER, K. (2006). Conjecturas e refutações. Trad. B. Bettencourt. Coimbra: Almedina.

ROSA, C. A. de P. (2012). História da ciência: da antiguidade ao renascimento científico. $-2^{\mathrm{a}}$. ed. - Brasília: FUNAG.

SPINELLI, M. (2006). Questões fundamentais da filosofia grega. São Paulo: Loyola.

WEISCHEDEL, W. (2000). A escada dos fundos da filosofia. Trad. E. D. Gil. São Paulo: Angra.

ZAMBRANO, M. (1995). O homem e o divino. Trad. C. Rodrigues e A. Guerra. Lisboa: Relógio D’Água. 